\title{
Fitness and Competitive Ability of Botrytis cinerea Field Isolates with Dual Resistance to SDHI and QoI Fungicides, Associated with Several $s d h B$ and the cytb G143A Mutations
}

\author{
T. Veloukas, P. Kalogeropoulou, A. N. Markoglou, and G. S. Karaoglanidis
}

First, second, and fourth authors: Aristotelian University of Thessaloniki, School of Agriculture, Laboratory of Plant Pathology, Thessaloniki, Greece; and third author: Agricultural University of Athens, Laboratory of Pesticide Science, Athens, Greece. Accepted for publication 21 October 2013.

\begin{abstract}
Veloukas, T., Kalogeropoulou, P., Markoglou, A. N., and Karaoglanidis, G. S. 2014. Fitness and competitive ability of Botrytis cinerea field isolates with dual resistance to SDHI and QoI fungicides, associated with several $s d h \mathrm{~B}$ and the cytb G143A mutations. Phytopathology 104:347356.

Respiration inhibitors such as the succinate dehydrogenase inhibitors (SDHIs) and the quinone outside inhibitors (QoIs) are fungicide classes with increasing relevance in gray mold control. However, recent studies have shown that dual resistance to both fungicide classes is a common trait in Botrytis cinerea populations from several hosts throughout the world. Resistance of B. cinerea to SDHIs is associated with several mutations in the $s d h \mathrm{~B}, s d h \mathrm{C}$, and $s d h \mathrm{D}$ genes, while resistance to QoIs, in most cases, is associated with the G143A mutation in the cytb gene. The objective of the current study was to investigate the fitness and the competitive ability of $B$. cinerea field strains possessing one of the $\mathrm{H} 272 \mathrm{Y} / \mathrm{R} / \mathrm{L}, \mathrm{N} 230 \mathrm{I}$, or P225F sdhB substitutions and the G143A mutation of $c y t$ b. Fitness parameters measured were (i) mycelial growth and conidia germination in vitro, (ii) aggressiveness and sporulation capacity in vivo, (iii) sclerotia production in vitro and sclerotia viability under different storage conditions, and (iv) sensitivity to oxidative stress imposed by diquat treatments. The competitive ability of the resistant iso-

lates was measured in the absence and presence of the SDHI fungicides boscalid and fluopyram selection pressure. The measurements of individual fitness components showed that the H272R/G143A isolates had the lower differences compared with the sensitive isolates. In contrast, the groups of H272Y/L/G143A, N230I/G143A, and P225F/G143A isolates showed reduced fitness values compared with the sensitive isolates. Isolates possessing only the cytb G143A substitution did not show any fitness cost. The competition experiments showed that, in the absence of fungicide selection pressure, after four disease cycles on apple fruit, the sensitive isolates dominated in the population in all the mixtures tested. In contrast, when the competition experiment was conducted under the selection pressure of boscalid, a gradual decrease in the frequency of sensitive isolates was observed, whereas the frequency of H272L and P225F isolates was increased. When the competition experiment was conducted in the presence of fluopyram, the sensitive isolates were eliminated even after the first disease cycle and the P225F mutants dominated in the population. Such results suggest that the $s d h \mathrm{~B}$ mutations may have adverse effects on the mutants. The observed dominance of sensitive isolates in the competition experiments conducted in the absence of fungicides suggest that the application of SDHIs in alternation schemes may delay the selection or reduce the frequency of SDHIresistant mutants.
\end{abstract}

Gray mold, caused by Botrytis cinerea Pers. (teleomorph Botryotinia fuckeliana), is among the most important diseases of several crops, causing significant yield losses worldwide (10). Fungicides registered for use against gray mold include several site-specific inhibitors (40). However, Botrytis cinerea represents a "high-risk" pathogen in the view of resistance development due to its high genetic variability, abundant sporulation, and polycyclic nature; its wide host range; and the high number of sprays required for its successful control (23). In the past, serious problems of fungicide resistance development have been reported, including resistance to most of the site-specific inhibitors used against the pathogen $(27,40)$.

At the end of the previous decade, boscalid, a succinate dehydrogenase inhibitor (SDHI), was registered in a prepacked mixture with the quinone outside inhibitor (QoI) pyraclostrobin. Newer molecules belonging to the SDHI group such as fluopyram or penthiopyrad are expected to be registered for the control of gray mold in the near future $(32,37)$. They all share a common mode of action consisting of the inhibition of the complex II in

Corresponding author: G. S. Karaoglanidis; E-mail address: gkarao@ agro.auth.gr

http://dx.doi.org/10.1094/PHYTO-07-13-0208-R

(c) 2014 The American Phytopathological Society the mitochondrial respiratory chain, also known as succinate: quinone oxidoreductase (SQR) or succinate dehydrogenase (sdh) (8). The enzyme is located in the inner mitochondrial membrane of eukaryotes and plays a crucial role in the tricarboxylic acid cycle and the mitochondrial electron transport chain, and its inhibition leads to a block of the cell energy cycle (25). Sdh catalyzes the oxidation of succinate to fumarate as part of the Krebs cycle while, following succinate oxidation, the enzyme transfers electrons directly to the quinone pool (8).

Pyraclostrobin, the boscalid partner registered for use against gray mold in a pre-packed mixture, is a QoI fungicide. QoIs constitutes one of the most important fungicide class used in agriculture, that has been developed from natural fungicidal compound derivatives (5). These compounds share a common mode of action which involves the inhibition of mitochondrial respiration by binding at the $\mathrm{Q}_{0}$ site of cytochrome $b c_{l}$ enzyme complex (also known as complex III). Inhibition of mitochondrial respiration is achieved by blocking the electron transfer between cytochrome $b$ and cytochrome $c_{l}$ which, in consequence, leads to a disruption of the energy cycle by suspending the production of ATP (5).

Shortly after the introduction of boscalid and pyraclostrobin into the spray programs, the first cases of dual-resistance development to both fungicides were reported in $B$. cinerea populations from grape in France (24) and kiwifruit in Greece (6). After these 
first reports of resistance to SDHIs and QoIs, additional cases in other countries or other crops were reported $(11,19,22,38,42)$.

Resistance to SDHIs in $B$. cinerea has been associated with several mutations in $s d h \mathrm{~B}, s d h \mathrm{C}$, and $s d h \mathrm{D}$ subunits $(1,24,33$, $38,44)$. Replacements of histidine by either arginine or tyrosine at codon 272 of the $s d h \mathrm{~B}(\mathrm{H} 272 \mathrm{R} / \mathrm{Y})$ were the most frequent mutations detected in field isolates $(11,24,38)$. A third mutation at the same codon, with the replacement of histidine by leucine (H272L) has also been detected at low frequencies $(24,38)$. In addition, five more mutations have been described in the $s d h \mathrm{~B}$ subunit of B. cinerea. Three of them were located at codon 225 leading to a substitution of proline by either phenylalanine, threonine, or leucine (P225F/T/L) and one mutation was located at codon 230 leading to an asparagine substitution by isoleucine (N230I) $(24,33,38)$. An additional mutation was detected in the $s d h \mathrm{D}$ subunit leading to histidine replacement by arginine at codon 132 (H132R) (24). Interestingly, these mutations confer differential levels of resistance to the different active ingredients of SDHIs. For instance, H272R/Y mutations confer moderate levels of resistance to boscalid, while sensitivity of H272R mutants to fluopyram remains unaffected and H272Y mutants show hypersensitivity to fluopyram. In contrast, mutations such as H272L or P225F confer high levels of resistance to boscalid and moderate or high levels of resistance to fluopyram, respectively (39). In addition to the $s d h$ mutations associated with resistance to SDHIs, the isolates with dual resistance to SDHIs and QoIs were found to possess the cytb G143A mutation, associated with high levels of resistance to QoIs $(6,24)$.

Implementation of anti-resistance strategies for respiration inhibitors is a difficult task in B. cinerea populations with dual resistance to QoIs and SDHIs. This is due to the variability in mutations associated with resistance to SDHIs, the diversity of molecules belonging to this fungicide class, and the differential effect of $s d h$ mutations on the sensitivity to the several SDHIs. Among the factors influencing the risk for resistance emergence, evolution, or decline, the fitness and competitive ability of the resistant strains are included. Mutations associated with fungicide resistance may display deleterious pleiotropic effects, known as fitness cost, that become apparent in the absence of fungicide selection pressure (17). Fitness can be defined as the survival and reproductive success of an allele, individual, or group (29). Evolution of fungicide resistance in fungal populations is largely dependent on the fitness of the strains and this has important implications on disease management (28). The evolution of fungicide resistance would be lessened if resistant subpopulations had lower parasitic or saprophytic fitness. In contrast, absence of fitness cost in the resistant fraction of the population would lead to a stable resistance frequency in the absence of fungicide selection pressure or to rapid development and increase of resistance frequency in the presence of fungicide selection pressure.

Detailed knowledge of the fitness of $B$. cinerea strains possessing dual resistance to QoIs and SDHIs is required in order to optimize gray mold management programs. Therefore, objectives of this study were to (i) measure several fitness components such as mycelial growth, sclerotia production, and viability under different storage conditions; sensitivity to oxidative stress; aggressiveness; and spore production in a set of field isolates possessing different $s d h \mathrm{~B}$ and the $c y t \mathrm{~b}$ G143A mutations and (ii) investigate the competitive ability of these mutants in both the absence and the presence of SDHI fungicide selection pressure.

\section{MATERIALS AND METHODS}

Fungal isolates. In all, $65 \mathrm{~B}$. cinerea isolates that had been previously characterized phenotypically and genotypically for resistance to several SDHIs and QoIs and for the associated $s d h \mathrm{~B}$ and cytb mutations were used in the study $(30,38,39)$. Of the tested isolates, 10 were sensitive to any fungicide, 10 were singly resistant to pyraclostrobin (QoIs) and possessed the G143A substitution, and the remaining isolates showed dual resistance to both SDHIs and QoIs and possessed the $s d h \mathrm{~B}$ H272R, H272Y, H272L, P225F, and N230I and cytb G143A mutations ( $n=10,10$, 6,9 , and 10 isolates, respectively). Due to the widespread presence of multiple fungicide resistance in the sampled fields, the isolates before final selection were also tested for sensitivity to other botryticides such as carbendazim, fludioxonil, fenhexamid, cyprodinil, and iprodione to exclude isolates showing resistance to them. Only isolates that were sensitive to all fungicides tested, singly resistant to QoIs, or with dual resistance to QoIs and SDHIs were used in this study. All the isolates originated from strawberry fruit and had been collected from commercial or experimental fields between 2008 and 2011 (Table 1). The isolates were maintained on potato dextrose agar (PDA) slants at $4^{\circ} \mathrm{C}$.

Genotyping of the isolates. All the selected isolates were confirmed to be $B$. cinerea using a polymerase chain reaction (PCR) restriction fragment length polymorphism (RFLP) method developed by Fournier et al. (13) that distinguishes $B$. cinerea from $B$. pseudocinerea, using the $B$. cinerea incompatibility locus (Bc-hch) as a molecular marker. The $s d h \mathrm{~B}$ mutations were identified using the primer-induced restriction analysis (PIRA)-PCR technique developed by Veloukas et al. (38). The presence or absence of the $s d h \mathrm{~B}$ mutations in the selected isolates was confirmed by sequencing of the $s d h \mathrm{~B}, s d h \mathrm{C}$, and $s d h \mathrm{D}$ subunit genes after amplifying them using primer pairs developed by Leroux et al. (24). The sequencing of the three subunits was conducted to exclude the probability of simultaneous presence of more than one $s d h$ mutation in the same selected isolate. The presence of the G143A mutation was detected using a real-time PCR technique developed by Samuel et al. (30). To reduce the risk of selecting similar haplotypes, all the isolates possessing the same mutations were selected from different fields.

Fungicide sensitivity assays. Measurements of sensitivity to boscalid and fluopyram were based on the inhibition of germ tube growth on yeast bacto acetate (YBA) agar medium according to a previously described technique $(37,38)$. Data on the isolates' sensitivity to boscalid and fluopyram are provided in Table 1. Measurements of sensitivity to the benzimidazole fungicide carbendazim (Pacarzim 50WP; Papaoikonomou Agrochemicals S.A., Thessalonika, Greece), the anilinopyrimidine cyprodinil (Chorus 50 WG; Syngenta Hellas, Athens, Greece), the phenylpyrrole fludioxonil (Geoxe 50 WG; Syngenta Hellas), the hydroxyanilide fenhexamid (Teldor $50 \mathrm{WG}$; BAYER Hellas, Athens, Greece), and the dicarboximide iprodione (Rovral Aquaflo $50 \mathrm{SC}$; BASF Hellas, Athens, Greece) was based on a previously described technique using discriminatory concentrations for each fungicide (22).

Fitness components. The following fitness components were determined: (i) mycelial growth in vitro, (ii) conidia germinability, (iii) sclerotia production in vitro and sclerotial viability, (iv) aggressiveness and spore production in vivo, and (v) sensitivity to oxidative stress. All the experiments were repeated in triplicate.

Mycelial growth. To measure mycelial growth, 5-mm mycelial plugs were removed from the margins of actively grown cultures and transferred to the center of fresh PDA plates for radial growth measurements. The plates were incubated at three different temperatures $\left(7,20\right.$, and $\left.30^{\circ} \mathrm{C}\right)$ under continuous light for 4 days; then, the colony diameter of each isolate was measured. For each isolate, four replicate plates were prepared.

Conidia germinability. B. cinerea cultures grown at $20^{\circ} \mathrm{C}$ and used for mycelial growth measurements were further incubated under the same conditions for an additional 10 days for production of conidia. At the end of the incubation period, the sporulating colonies were rinsed with sterile distilled water. The 
conidial suspensions were filtered through double-layered cheesecloth and the spore concentration in the suspensions was adjusted to $5 \times 10^{4}$ conidia $/ \mathrm{ml}$. Aliquots $(30 \mu \mathrm{l})$ of each suspension were spread on $6-\mathrm{cm}$ water agar plates. After $18 \mathrm{~h}$ of incubation at 7 , 20 , or $30^{\circ} \mathrm{C}$, conidia were checked for germination. A conidium was considered germinated if the germ tube had length at least the half of the conidium length. In total, 100 conidia were scored per plate and four plates per isolate were prepared for each incubation temperature.

Sclerotia production in vitro and sclerotia viability. To measure sclerotia production in vitro, PDA plates were inoculated with a 5 -mm mycelial plug and incubated in the dark at two different temperatures, 7 and $20^{\circ} \mathrm{C}$, for 9 or 6 weeks, respectively. For each isolate-temperature combination, four replicate plates were prepared. After the end of the incubation period, the number of sclerotia formed in each plate was counted visually.

After counting the number of sclerotia in each plate, they were removed from nutrient medium using a fine scalpel, surface sterilized by immersing them for $1 \mathrm{~min}$ in $70 \%$ (vol/vol) ethanol, and rinsed twice in sterile water, according to a procedure previously described by Mosbach et al. (26). Then, they were air dried in the laminar-flow and collected in Falcon tubes. The sclerotia were stored at $-20,20$, and $37^{\circ} \mathrm{C}$. Three replicate tubes were prepared per isolate-storage temperature, with 60 sclerotia in each tube. The viability of sclerotia was assessed after 1,2, and 4 months of storage. Twenty sclerotia per isolate-storage temperature combination from each replicate tube were transferred on PDA plates and incubated for 3 days at $20^{\circ} \mathrm{C}$ in the dark. At the end of the incubation period, the number of germinated sclerotia was counted.

Aggressiveness in vivo. The aggressiveness of the selected isolates was measured on intact primary leaves of bean (Phaseolus vulgaris L. 'Prespes') plants. Inoculum was produced on PDA after 10 days of culture cultivation at $20^{\circ} \mathrm{C}$ under continuous light. Inoculum suspension were prepared in Gamborg Minimal medium (3 $\mathrm{g}$ of Gamborg B5 basal salt mixtures, $1.36 \mathrm{~g}$ of $\mathrm{KH}_{2} \mathrm{PO}_{4}$, and $9.9 \mathrm{~g}$ of glucose per liter of medium) (26) and adjusted to a concentration of $2 \times 10^{5}$ spores $\mathrm{ml}^{-1}$. Inoculation was carried out by pipetting $10 \mu \mathrm{l}$ of conidial suspension at two different points on the adaxial surface of leaves. After inoculation, the plants were covered with a plastic bag to maintain high humidity, transferred to the incubation chambers, and remained covered with the plastic bags for the entire incubation period. The inoculated plants were incubated for 3 days at 7,20 , and $27^{\circ} \mathrm{C}$ and the infection was scored by measuring the lesion diameter around the inoculation point. In total, 12 leaves (6 plants, 24 inoculation points) were inoculated per isolate-incubation temperature combination.

Conidial production in vivo. After measurement of aggressiveness, leaf segments $\left(\approx 20 \mathrm{~mm}^{2}\right)$ with sporulating lesions were removed with the aid of a 5-mm-diameter cork borer. One segment was removed from each leaf and 12 leaves were tested per isolate. Each leaf segment was placed in $3 \mathrm{ml}$ of distilled water in plastic tubes and vortexed for $20 \mathrm{~s}$ to detach the conidia from the lesion; subsequently, the leaf segment was removed. Droplets of the conidial suspension were placed on the hemocytometer and the number of conidia was counted. Four replicate droplets were counted for each tube. The number was expressed as the number of conidia per square millimeter of diseased leaf surface. Measurements of conidial production were conducted only on lesions obtained from plants incubated at $20^{\circ} \mathrm{C}$, because conidial production on plants incubated at 7 or $27^{\circ} \mathrm{C}$ was sparse.

Sensitivity to oxidative stress. Sensitivity of the isolates to oxidative stress was determined by measuring inhibition of mycelial growth and conidia germination on PDA amended with the herbicide diquat (Diquat 20SL; Syngenta Hellas) at the rates of $0,1,10,10$, and $1,000 \mu \mathrm{g} \mathrm{ml}{ }^{-1}$. The relative inhibition of mycelial growth or conidial germination for each isolate was
TABLE 1. List of Botrytis cinerea isolates used in the study and their sensitivity to boscalid and fluopyram

\begin{tabular}{|c|c|c|c|c|}
\hline \multirow[b]{2}{*}{ Isolate } & \multirow[b]{2}{*}{ Mutation } & \multirow[b]{2}{*}{ Year $^{\mathrm{w}}$} & \multicolumn{2}{|c|}{$\mathrm{EC}_{50}\left(\mu \mathrm{g} \mathrm{ml}^{-1}\right)^{\mathrm{x}}$} \\
\hline & & & Boscalid & Fluopyram \\
\hline 26 & $\ldots$ & 2008 & 0.13 & 0.15 \\
\hline 38 & $\ldots$ & 2008 & 0.15 & 0.15 \\
\hline S3 & $\ldots$ & 2009 & 0.16 & 0.13 \\
\hline S21 & $\ldots$ & 2009 & 0.13 & 0.13 \\
\hline $\mathrm{S} 38$ & $\ldots$ & 2009 & 0.15 & 0.15 \\
\hline M3 & $\ldots$ & 2011 & 0.13 & 0.12 \\
\hline M32 & $\ldots$ & 2011 & 0.13 & 0.13 \\
\hline M157 & $\ldots$ & 2011 & 0.15 & 0.14 \\
\hline P 1.1 & $\ldots$ & 2011 & 0.15 & 0.15 \\
\hline P1.21 & $\ldots$ & 2011 & 0.14 & 0.14 \\
\hline \multicolumn{5}{|l|}{ Single $y$} \\
\hline 37 & G143A & 2008 & 0.09 & 0.11 \\
\hline 42 & G143A & 2008 & 0.12 & 0.10 \\
\hline 46 & G143A & 2008 & 0.11 & 0.09 \\
\hline $\mathrm{S} 3$ & G143A & 2009 & 0.15 & 0.15 \\
\hline $\mathrm{BcS} 2$ & G143A & 2010 & 0.09 & 0.13 \\
\hline $\mathrm{BcS} 8$ & G143A & 2010 & 0.10 & 0.12 \\
\hline $\mathrm{BcS} 15$ & G143A & 2010 & 0.15 & 0.15 \\
\hline $\mathrm{BcS} 27$ & G143A & 2010 & 0.12 & 0.15 \\
\hline M1 & G143A & 2011 & 0.16 & 0.10 \\
\hline M8 & G143A & 2011 & 0.08 & 0.12 \\
\hline \multicolumn{5}{|l|}{ Dual $^{2}$} \\
\hline 19 & $\mathrm{H} 272 \mathrm{R} / \mathrm{G} 143 \mathrm{~A}$ & 2008 & 2.4 & 0.1 \\
\hline S8 & $\mathrm{H} 272 \mathrm{R} / \mathrm{G} 143 \mathrm{~A}$ & 2009 & 2.2 & 0.09 \\
\hline S16 & $\mathrm{H} 272 \mathrm{R} / \mathrm{G} 143 \mathrm{~A}$ & 2009 & 2.1 & 0.2 \\
\hline S30 & $\mathrm{H} 272 \mathrm{R} / \mathrm{G} 143 \mathrm{~A}$ & 2009 & 2.3 & 0.1 \\
\hline $\mathrm{BcS} 13$ & $\mathrm{H} 272 \mathrm{R} / \mathrm{G} 143 \mathrm{~A}$ & 2010 & 2.0 & 0.1 \\
\hline M12 & H272R/G143A & 2011 & 2.3 & 0.1 \\
\hline M43 & $\mathrm{H} 272 \mathrm{R} / \mathrm{G} 143 \mathrm{~A}$ & 2011 & 2.7 & 0.1 \\
\hline M77 & $\mathrm{H} 272 \mathrm{R} / \mathrm{G} 143 \mathrm{~A}$ & 2011 & 2.3 & 0.1 \\
\hline M101 & $\mathrm{H} 272 \mathrm{R} / \mathrm{G} 143 \mathrm{~A}$ & 2011 & 2.0 & 0.1 \\
\hline M156 & $\mathrm{H} 272 \mathrm{R} / \mathrm{G} 143 \mathrm{~A}$ & 2011 & 2.1 & 0.1 \\
\hline 17 & H272Y/G143A & 2008 & 2.4 & 0.01 \\
\hline 30 & $\mathrm{H} 272 \mathrm{Y} / \mathrm{G} 143 \mathrm{~A}$ & 2008 & 1.9 & 0.01 \\
\hline S35 & H272Y/G143A & 2009 & 2.1 & 0.008 \\
\hline $\mathrm{S} 40$ & $\mathrm{H} 272 \mathrm{Y} / \mathrm{G} 143 \mathrm{~A}$ & 2009 & 2.0 & 0.01 \\
\hline $\mathrm{BcS} 1$ & $\mathrm{H} 272 \mathrm{Y} / \mathrm{G} 143 \mathrm{~A}$ & 2010 & 3.7 & 0.01 \\
\hline M50 & $\mathrm{H} 272 \mathrm{Y} / \mathrm{G} 143 \mathrm{~A}$ & 2011 & 2.2 & 0.07 \\
\hline M60 & H272Y/G143A & 2011 & 1.5 & 0.006 \\
\hline M10 & $\mathrm{H} 272 \mathrm{Y} / \mathrm{G} 143 \mathrm{~A}$ & 2011 & 3.7 & 0.01 \\
\hline M144 & $\mathrm{H} 272 \mathrm{Y} / \mathrm{G} 143 \mathrm{~A}$ & 2011 & 4.3 & 0.01 \\
\hline M153 & H272Y/G143A & 2011 & 3.8 & 0.07 \\
\hline $\mathrm{S} 12$ & $\mathrm{H} 272 \mathrm{~L} / \mathrm{G} 143 \mathrm{~A}$ & 2009 & $>50$ & 4.4 \\
\hline SV4.23 & H272L/G143A & 2011 & $>50$ & 3.9 \\
\hline SV4.9 & $\mathrm{H} 272 \mathrm{~L} / \mathrm{G} 143 \mathrm{~A}$ & 2011 & $>50$ & 4.4 \\
\hline SV4.39 & $\mathrm{H} 272 \mathrm{~L} / \mathrm{G} 143 \mathrm{~A}$ & 2011 & $>50$ & 4.6 \\
\hline P4.15 & $\mathrm{H} 272 \mathrm{~L} / \mathrm{G} 143 \mathrm{~A}$ & 2011 & $>50$ & 3.2 \\
\hline КП47 & $\mathrm{H} 272 \mathrm{~L} / \mathrm{G} 143 \mathrm{~A}$ & 2011 & $>50$ & 4.3 \\
\hline M31 & $\mathrm{N} 230 \mathrm{I} / \mathrm{G} 143 \mathrm{~A}^{\mathrm{b}}$ & 2011 & 4.4 & 1.4 \\
\hline M181 & N230I/G143A & 2011 & 4.4 & 1.6 \\
\hline 273 (S7) & N230I/G143A & 2009 & 4.1 & 2.0 \\
\hline $\mathrm{BcS} 3$ & N230I/G143A & 2010 & 3.7 & 1.8 \\
\hline $\mathrm{BcS} 23$ & N230I/G143A & 2010 & 4.8 & 1.6 \\
\hline $\mathrm{BcS} 35$ & N230I/G143A & 2010 & 4.6 & 1.4 \\
\hline $286(\mathrm{~S} 20)$ & N230I/G143A & 2009 & 4.1 & 1.6 \\
\hline SV11.5 & N230I/G143A & 2011 & 4.8 & 1.8 \\
\hline SV6.1 & N230I/G143A & 2011 & 4.4 & 1.0 \\
\hline SV2.8 & N230I/G143A & 2011 & 4.8 & 1.4 \\
\hline BcS6 & P225F/G143A & 2010 & $>50$ & 14.2 \\
\hline $\mathrm{BcS} 22$ & P225F/G143A & 2010 & $>50$ & 15.2 \\
\hline $\mathrm{BcS} 24$ & P225F/G143A & 2010 & $>50$ & 16.3 \\
\hline V18 & P225F/G143A & 2011 & $>50$ & 14.3 \\
\hline V34 & P225F/G143A & 2011 & $>50$ & 18.4 \\
\hline SV3.11 & P225F/G143A & 2011 & $>50$ & 12.1 \\
\hline SV3.3 & P225F/G143A & 2011 & $>50$ & 14.6 \\
\hline SV2.4 & $\mathrm{P} 225 \mathrm{~F} / \mathrm{G} 143 \mathrm{~A}$ & 2011 & $>50$ & 15.8 \\
\hline SV3.10 & P225F/G143A & 2011 & $>50$ & 19.5 \\
\hline
\end{tabular}

w Year of isolation.

${ }^{x}$ Fungicide $50 \%$ effective concentration.

${ }^{y}$ Isolates with single resistance to pyraclostrobin (quinone outside inhibitors [QoIs]) associated with the G143A mutation in cytb.

${ }^{\mathrm{z}}$ Isolates with dual resistance to boscalid (succinate dehydrogenase inhibitors) and pyraclostrobin (QoIs) associated with $\mathrm{H} 272 \mathrm{~L} / \mathrm{R} / \mathrm{Y}$, N230I, or P225F mutations in $s d h \mathrm{~B}$ and the G143A mutation in cytb, respectively. 
calculated after 4 days or $24 \mathrm{~h}$, respectively, of incubation at $20^{\circ} \mathrm{C}$ in the dark. For each isolate, four replicate plates with mycelial cultures or conidial suspensions were prepared and measurements were conducted as described previously in mycelial growth measurement and conidia germinability assays.

Competition experiments. Experimental design. Two types of competition experiments were conducted. In the first type of experiment, the competitive ability of $s d h \mathrm{~B}$ mutants and sensitive (S) isolates was compared in separate pairs of each mutated genotype, with the $S$ isolates at an initial ratio of $1: 1$, in the absence of any fungicide selection pressure. In the second type of competition experiment, instead of using conidial mixtures in separate pairs of sensitive and mutated isolates, mixed-genotype inoculums were prepared containing the S, H272R/G143A, H272Y/G143A, H272L/G143A, N230I/G143A, and P225F/G143A isolates at an initial ratio of $1: 1: 1: 1: 1: 1$. The competition experiment with mixed-genotype inoculum was conducted both in the absence of fungicide selection pressure and in the presence of either boscalid or fluopyram selection pressure.

Artificial inoculations of apple fruit. Conidia for each of the isolates used in the study were produced as described previously and inoculum for the artificial inoculations was prepared by mixing appropriate volumes of conidial suspensions of all the isolates of each mutated genotype and of all the wild-type isolates. The final conidial suspension used for the first cycle of artificial inoculations contained a concentration of $5 \times 10^{5}$ conidia/ml.

Artificial inoculations were conducted on apple fruit ('Golden Smith') collected from an apple orchard that did not receive any fungicide treatment before harvest. Apple fruit were disinfected by immersion in $5 \%$ ( $\mathrm{vol} / \mathrm{vol})$ sodium hypochlorite solution for $1 \mathrm{~min}$, rinsed three times in sterile deionized water, and subsequently air dried. Apple fruit used for the competition experiment under the selection pressure of boscalid or fluopyram were immersed for $1 \mathrm{~min}$ in aqueous fungicide suspensions of each active ingredient at $1.0 \mu \mathrm{g} \mathrm{ml}^{-1}$. This concentration was selected as being sublethal in vivo for isolates of wild-type sensitivity (39). The fungicides used were the commercial product Cantus $50 \mathrm{WG}$ (boscalid at $500 \mathrm{~g} \mathrm{liter}^{-1}$; BASF) and a fluopyram experimental formulation (AE C656948 $500 \mathrm{SC}$, fluopyram at $500 \mathrm{~g} \mathrm{liter}^{-1}$; Bayer CropScience). Inoculation was carried out by pipetting $20 \mu \mathrm{l}$ of a conidial suspension on four wounds inflicted near the fruit equator using a sterile fine needle. Five apple fruit were inoculated per isolate group pair and fungicide treatment. Then, fruit were placed on wire mesh platforms in plastic boxes (23 by 31 by $10 \mathrm{~cm}$ [length by width by height]). Water $(20 \mathrm{ml})$ was added in each box and then covered to maintain high relative humidity. Following inoculation, the fruit were incubated at $20^{\circ} \mathrm{C}$ for 10 days. Then diseased fruit were longitudinally cut into halves and incubated for an additional $48 \mathrm{~h}$ to induce sporulation on the cut surface. Then, the spores were harvested in sterile distilled water and a new conidial suspension was prepared for the next disease cycle. The experiments were terminated after four disease cycles and repeated twice.

Measurement of SDHI-resistance frequency. Frequency of resistance to SDHIs was measured after the end of each disease cycle. For this purpose, the inoculum prepared for the next disease cycle was used. In the experiment conducted to measure the competitive ability of $s d h \mathrm{~B}$ mutants in separate pairs with the sensitive isolates, frequency of resistance to boscalid was determined. In the experiment conducted to measure competitive ability using mixed inocula of all the $s d h \mathrm{~B}$ mutants with sensitive isolates at the rate of $1: 1: 1: 1: 1: 1$ in the presence or absence of SDHIs selection pressure, frequency of resistance to both boscalid and fluopyram was determined. Aliquots $(30 \mu \mathrm{l})$ from each conidial suspension originated from separate fruit and were spread on YBA agar plates amended with boscalid or fluopyram at the discriminatory rates of $1 \mu \mathrm{g} \mathrm{ml}^{-1}$. The concentration of boscalid at
$1 \mu \mathrm{g} \mathrm{ml}{ }^{-1}$ inhibits the germination of boscalid-sensitive spores, while boscalid-resistant spores germinate normally (39). Similarly, the concentration of fluopyram at $1 \mu \mathrm{g} \mathrm{ml}^{-1}$ inhibits the germination of the wild-type isolate spores and the spores of the $\mathrm{H} 272 \mathrm{R} / \mathrm{Y}$ mutants, while spores of the H272L, N230I, and P225F mutants germinate normally (39). Three replicate plates were prepared per each conidial suspension. The plates were incubated for $18 \mathrm{~h}$ at $20^{\circ} \mathrm{C}$; then, 100 conidia per plate were examined for germination microscopically. In total, 300 conidia were checked for germination per each conidial suspension.

$\mathrm{Sdh} B$ mutation identification. The identification of the $s d h \mathrm{~B}$ mutations was conducted in isolates obtained after the end of the fourth disease cycle from fruit that had been used in the competition experiment with mixed inocula of all the $s d h \mathrm{~B}$ mutants with sensitive isolates at the rate of $1: 1: 1: 1: 1: 1$ in the presence or absence of SDHI selection pressure. For this purpose, 10 singlespore isolates were obtained from each diseased fruit. In total, 50 isolates were tested per treatment. The isolates were allowed to sporulate on PDA and the conidia were used for the phenotypic characterization of the isolates. The phenotypic characterization was conducted using the discriminatory concentrations of boscalid or fluopyram at $1 \mu \mathrm{g} \mathrm{ml}^{-1}$, as described previously. Based on this procedure, the isolates were grouped as sensitive to both fungicides ( $\mathrm{S}$ isolates), isolates resistant to boscalid but sensitive to fluopyram ( $\mathrm{B}^{\mathrm{R}} \mathrm{F}^{\mathrm{S}}$ isolates, corresponding to $\mathrm{H} 272 \mathrm{R} / \mathrm{Y}$ mutants), and isolates resistant to both boscalid and fluopyram $\left(\mathrm{B}^{\mathrm{R}} \mathrm{F}^{\mathrm{R}}\right.$ isolates, corresponding to $\mathrm{H} 272 \mathrm{~L}, \mathrm{P} 225 \mathrm{~F}$, or N230I mutants). The identification of $s d h \mathrm{~B}$ mutations was conducted on isolates of $\mathrm{B}^{\mathrm{R}} \mathrm{F}^{\mathrm{S}}$ and $\mathrm{B}^{\mathrm{R}} \mathrm{F}^{\mathrm{R}}$ phenotypes, using a PIRA-PCR technique developed previously (38).

Data analysis. Data of the three independent replications, for each fitness component tested, were pooled after testing homogeneity of variance using the Levene test and subjected to an analysis of variance. Analysis of percentage data was based on arcsinesquare root-transformed percentage values. Mean values of each genotype group were compared using the Fisher's protected least significant difference test at $P=0.05$. In the competition experiments, the observed frequencies (\%) of resistance phenotypes and the frequencies of specific mutants were compared with the initial frequencies using the $\chi^{2}$ test. All of the statistical analysis tests were performed using SPSS Statistics (version 11.0; IBM, NY).

\section{RESULTS}

Fitness components. Mycelial growth. Isolates of wild-type sensitivity and isolates with single resistance to QoIs showed, as groups, higher mycelial growth at all three temperatures tested. Mycelial growth similar to that of the sensitive isolates was found only for the $\mathrm{H} 272 \mathrm{R} / \mathrm{G} 143 \mathrm{~A}$ isolates at $7^{\circ} \mathrm{C}$ and the $\mathrm{H} 272 \mathrm{~L} /$ $\mathrm{G} 143 \mathrm{~A}$ isolates at $20^{\circ} \mathrm{C}$ (Table 2). At the lower temperature tested $\left(7^{\circ} \mathrm{C}\right)$, the lower mycelial growth was observed in P225F/G143A and H272L/G143A isolates with values of 34.1 and $35.5 \mathrm{~mm}$, respectively. At the optimal temperature of $20^{\circ} \mathrm{C}$, lower mycelial growth was observed in $\mathrm{H} 272 \mathrm{Y} / \mathrm{G} 143 \mathrm{~A}$ isolates, with a value of $69.6 \mathrm{~mm}$; whereas, at the temperature of $30^{\circ} \mathrm{C}$, lower mycelial growth was observed in H272Y/G143A, H272L/G143A, and $\mathrm{P} 225 \mathrm{~F} / \mathrm{G} 143 \mathrm{~A}$ isolates, with values of $51.2,51.7$, and $53.8 \mathrm{~mm}$, respectively (Table 2).

Spore germination. In all of the incubation temperatures, higher absolute values of conidial germinability were observed in sensitive isolates. Interestingly, at $30^{\circ} \mathrm{C}$, only the $\mathrm{H} 272 \mathrm{Y} / \mathrm{G} 143 \mathrm{~A}$ isolates showed spore germination values lower than those of the wild-type isolates (Table 2). At the limiting temperature of $7^{\circ} \mathrm{C}$, the H272L/G143A and N230I/G143A isolates showed lower spore germination values of 15.7 and $39.8 \%$, respectively, while H272R/G143A and H272Y/G143A isolates showed higher $(P<$ $0.05)$ spore germination values of 60.4 and $54.3 \%$, respectively. 
In contrast, at the same temperature, P225F/G143A isolates showed germination values similar to that of wild-type isolates (Table 2). At the optimum temperature of $20^{\circ} \mathrm{C}$, the $\mathrm{H} 272 \mathrm{R}$ and the N230I isolates showed spore germination values similar to that of sensitive isolates while the P225F/G143A and H272L/G143A isolates showed the lower spore germination values (Table 2).

Sclerotia production and viability. All the isolates included in the study produced sclerotia under both incubation temperatures, independently of their genotype. However, there were marked differences among them. The H272L/G143A isolates produced significantly $(P<0.05)$ more sclerotia than the other groups of isolates under both incubation temperatures (Table 3 ). A relatively high number of sclerotia was also produced by the H272R/G143A isolates. Nevertheless, it is worth mentioning that, although precise measurements were not conducted, sclerotia size in H272L/ G143A and H272R/G143A was obviously lower compared with the size of sclerotia produced by the remaining isolate groups. The lower number of sclerotia in both incubation temperatures was produced by the sensitive isolates, the isolates with single resistance to QoIs, and the H272Y/G143A and P225F/G143A mutants (Table 3).

Measurements of sclerotia viability showed that, in all three storage temperatures, the sclerotia viability of all the isolates remained unaffected after 1 month of storage, with germination percentages of $100 \%$ (Table 4). Similarly, sclerotia of all the isolates retained their viability at levels of $100 \%$ when they were stored at either -20 or $20^{\circ} \mathrm{C}$. However, a significant reduction was observed in the viability of sclerotia stored at $37^{\circ} \mathrm{C}$ after 2 months of storage. The higher viability was observed in the sclerotia of the sensitive and the G143A isolates, with values of 34.6 and $32.8 \%$, respectively, while sclerotia of the H272L/G143A isolates totally lost their viability. A marked reduction of sclerotia viability was observed after 4 months of storage at all three storage temperatures. Interestingly, after 4 months of storage at $37^{\circ} \mathrm{C}$, the sclerotia of all the isolates, independent of their genotype, totally lost their viability. For all the genotype groups, the higher sclerotial viability levels were observed when sclerotia were stored for 4 months at $20^{\circ} \mathrm{C}$. At this temperature, the higher $(P<0.05)$ viability percentage values were observed in the sensitive isolates and the G143A, H272Y/G143A, and N230I/ G143A mutants. In contrast, sclerotia of H272L/G143A and P225F/G143A mutants showed the lower viability $(P<0.05)$ at this temperature (Table 4). Similarly, when sclerotia were stored at $-20^{\circ} \mathrm{C}$, the higher viability was observed in sensitive and G143A isolates, with values of 86.6 and $89.8 \%$ of germinated sclerotia, respectively, while the lower germination values were observed for the H272L/G143A and P225F/G143A mutants, with mean values of 43.3 and $28.7 \%$, respectively (Table 4 ).
Aggressiveness and spore production. All the isolates used in the study were found to be pathogenic on intact primary bean leaves. In all three temperatures tested, the longer lesion diameters were observed on the leaves inoculated with the H272R/ G143A isolates, with mean values of $16.7,37.6$, and $29.5 \mathrm{~mm}$ at 7,20 , and $27^{\circ} \mathrm{C}$, respectively (Table 2). Aggressiveness values for the H272R/G143A isolates were similar $(P>0.05)$ to the respective values for the sensitive isolates at 20 and $27^{\circ} \mathrm{C}$, whereas they were higher $(P<0.05)$ than that of the sensitive isolates at $7^{\circ} \mathrm{C}$. In all three temperatures tested, the H272L/G143A and $\mathrm{P} 225 \mathrm{~F} / \mathrm{G} 143 \mathrm{~A}$ isolates showed lower lesion diameter values compared with the lesion diameters caused by the sensitive isolates or the $\mathrm{H} 272 \mathrm{R} / \mathrm{Y} / \mathrm{G} 143 \mathrm{~A}$ and the $\mathrm{N} 230 \mathrm{I} / \mathrm{G} 143 \mathrm{~A}$ isolates (Table 2).

Measurement of spore production was conducted only on plants incubated at $20^{\circ} \mathrm{C}$ because sporulation was sparse on plants incubated at either 7 or $27^{\circ} \mathrm{C}$. The higher sporulation capacity was observed in the sensitive and H272R/G143A isolates, with mean values of $0.11 \times 10^{4}$ spores $/ \mathrm{mm}^{2}$ of lesion for both groups of isolates (Table 2). In contrast, H272L/G143A and P225F/G143A isolates showed the lower $(P<0.05)$ spore production capacity, with mean values of 0.012 and $0.013 \times 10^{4}$ spores $/ \mathrm{mm}^{2}$ of lesion (Table 2).

Sensitivity to oxidative stress. Spore germination of all the isolates included in the study was not affected in the low diquat concentrations tested of 1 and $10 \mu \mathrm{g} \mathrm{ml}^{-1}$ whereas, at the higher concentration tested of $1,000 \mu \mathrm{g} \mathrm{ml}^{-1}$, spore germination was completely inhibited. However, differences were apparent at the concentration of $100 \mu \mathrm{g} \mathrm{ml}{ }^{-1}$, in which germination of the sensitive isolates and the G143A mutants remained unaffected

TABLE 3. Sclerotia production of Botrytis cinerea isolates possessing different $s d h \mathrm{~B}$ or the $c y t \mathrm{~b}$ G143A mutations, grown on PDA medium and incubated for 6 and 9 or 3 and 6 weeks at 7 or $20^{\circ} \mathrm{C}$, respectively

\begin{tabular}{|c|c|c|c|c|}
\hline \multirow[b]{3}{*}{ Genotype } & \multicolumn{4}{|c|}{ Number of sclerotia ${ }^{z}$} \\
\hline & \multicolumn{2}{|c|}{$7^{\circ} \mathrm{C}$} & \multicolumn{2}{|c|}{$20^{\circ} \mathrm{C}$} \\
\hline & 6 weeks & 9 weeks & 3 weeks & 6 weeks \\
\hline Sensitive & $3.8 \mathrm{e}$ & $19.2 \mathrm{~d}$ & $8.4 \mathrm{~b}$ & $13.9 \mathrm{c}$ \\
\hline G143A & $4.5 \mathrm{e}$ & $21.5 \mathrm{~d}$ & $10.6 \mathrm{~b}$ & $12.2 \mathrm{c}$ \\
\hline H272R/G143A & $35.0 \mathrm{~b}$ & $39.2 \mathrm{~b}$ & $17.9 \mathrm{~b}$ & $37.5 \mathrm{~b}$ \\
\hline H272Y/G143A & $10.3 \mathrm{de}$ & $26.1 \mathrm{~cd}$ & $13.2 \mathrm{~b}$ & $15.0 \mathrm{c}$ \\
\hline H272L/G143A & $48.3 \mathrm{a}$ & $53.6 \mathrm{a}$ & $52.9 \mathrm{a}$ & $56.2 \mathrm{a}$ \\
\hline N230I/G143A & $25.8 \mathrm{bc}$ & $31.6 \mathrm{bc}$ & $11.9 \mathrm{~b}$ & $17.5 \mathrm{c}$ \\
\hline $\mathrm{P} 225 \mathrm{~F} / \mathrm{G} 143 \mathrm{~A}$ & $15.9 \mathrm{~cd}$ & $17.7 \mathrm{~d}$ & $11.5 \mathrm{~b}$ & $19.8 \mathrm{c}$ \\
\hline
\end{tabular}

${ }^{\mathrm{z}}$ Number of sclerotia per plate. Mean values of groups followed by the same letter are not significantly different according to Fisher's protected least significant difference test at $P=0.05$.

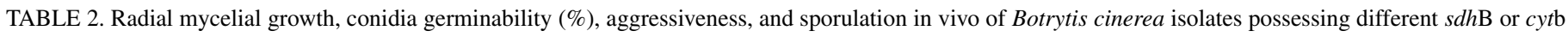
G143A mutations

\begin{tabular}{|c|c|c|c|c|c|c|c|c|c|c|}
\hline \multirow[b]{3}{*}{ Genotype } & \multicolumn{10}{|c|}{ Fitness component $^{\mathrm{v}}$} \\
\hline & \multicolumn{3}{|c|}{ Mycelial growth $(\mathrm{mm})^{\mathrm{w}}$} & \multicolumn{3}{|c|}{ Conidia germinability $(\%)^{\mathrm{x}}$} & \multicolumn{3}{|c|}{ Aggressiveness $(\mathrm{mm})^{\mathrm{y}}$} & \multirow{2}{*}{$\begin{array}{c}\text { Sporulation }^{2} \\
20^{\circ} \mathrm{C}\end{array}$} \\
\hline & $7^{\circ} \mathrm{C}$ & $20^{\circ} \mathrm{C}$ & $30^{\circ} \mathrm{C}$ & $7^{\circ} \mathrm{C}$ & $20^{\circ} \mathrm{C}$ & $30^{\circ} \mathrm{C}$ & $7^{\circ} \mathrm{C}$ & $20^{\circ} \mathrm{C}$ & $27^{\circ} \mathrm{C}$ & \\
\hline Sensitive & $45.5 \mathrm{a}$ & $79.8 \mathrm{a}$ & $66.0 \mathrm{a}$ & $72.7 \mathrm{a}$ & $96.5 \mathrm{a}$ & $92.4 \mathrm{a}$ & $15.7 \mathrm{~b}$ & $37.1 \mathrm{a}$ & $29.3 \mathrm{a}$ & $0.108 \mathrm{a}$ \\
\hline G143A & $42.8 \mathrm{a}$ & $77.9 \mathrm{ab}$ & $66.5 \mathrm{a}$ & $75.2 \mathrm{a}$ & $96.3 \mathrm{a}$ & $93.5 \mathrm{a}$ & $16.2 \mathrm{ab}$ & $38.0 \mathrm{a}$ & $28.9 \mathrm{a}$ & $0.106 \mathrm{a}$ \\
\hline H272R/G143A & $42.3 \mathrm{a}$ & $75.4 \mathrm{~b}$ & $57.4 \mathrm{~b}$ & $60.4 \mathrm{bc}$ & $91.5 \mathrm{ab}$ & $86.8 \mathrm{ab}$ & $16.7 \mathrm{a}$ & $37.7 \mathrm{a}$ & $29.6 \mathrm{a}$ & $0.114 \mathrm{a}$ \\
\hline H272Y/G143A & $39.6 \mathrm{~b}$ & $69.6 \mathrm{~d}$ & $51.2 \mathrm{c}$ & $54.3 \mathrm{c}$ & $88.0 \mathrm{bc}$ & $85.1 \mathrm{~b}$ & $17.0 \mathrm{a}$ & $34.5 \mathrm{~b}$ & $26.9 \mathrm{~b}$ & $0.072 \mathrm{~b}$ \\
\hline H272L/G143A & $35.5 \mathrm{c}$ & $79.2 \mathrm{a}$ & $51.7 \mathrm{c}$ & $15.7 \mathrm{e}$ & $86.1 \mathrm{~cd}$ & $89.3 \mathrm{ab}$ & $12.0 \mathrm{~d}$ & $17.3 \mathrm{e}$ & $16.6 \mathrm{~d}$ & $0.012 \mathrm{c}$ \\
\hline N230I/G143A & $39.6 \mathrm{~b}$ & $72.2 \mathrm{c}$ & $56.7 \mathrm{~b}$ & $39.8 \mathrm{~d}$ & $93.6 \mathrm{a}$ & $91.5 \mathrm{ab}$ & $14.0 \mathrm{c}$ & $31.4 \mathrm{c}$ & $23.9 \mathrm{c}$ & $0.075 \mathrm{~b}$ \\
\hline P225F/G143A & $34.1 \mathrm{c}$ & $72.6 \mathrm{c}$ & $53.8 \mathrm{c}$ & $68.7 \mathrm{ab}$ & $81.8 \mathrm{~d}$ & $86.8 \mathrm{ab}$ & $11.8 \mathrm{~d}$ & $22.0 \mathrm{~d}$ & $17.1 \mathrm{~d}$ & $0.013 \mathrm{c}$ \\
\hline
\end{tabular}

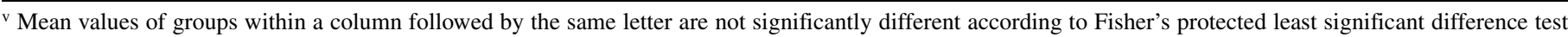
at $P=0.05$. Percentage values were arcsine transformed before the statistical analysis.

${ }^{\mathrm{w}}$ Mycelial growth was measured after 4 days of incubation on potato dextrose agar.

${ }^{x}$ Germination of conidia was measured after $24 \mathrm{~h}$ of incubation on water agar.

y Aggressiveness was measured as lesion diameter on intact bean primary leaves ('Prespes').

${ }^{\mathrm{z}}$ Number of spores $\left(\times 10^{4}\right)$ per square millimeter of lesion produced on bean leaves. 
while, in isolates possessing the $s d h \mathrm{~B}$ mutations, relatively high inhibition values were observed (Table 5). Similarly, mycelia growth was only slightly affected at the low diquat concentrations of 1 and $10 \mu \mathrm{g} \mathrm{ml}^{-1}$. However, at the higher concentrations tested of 100 and $1,000 \mu \mathrm{g} \mathrm{ml}^{-1}$, a strong reduction in mycelia growth was observed, in particular for the groups of H272R/L/G143A and P225F/G143A isolates (Table 5).

Competitive ability. Competition experiments conducted using separate pairs of each mutated genotype with the $S$ isolates at an initial ratio of $1: 1$ showed that all the $s d h \mathrm{~B}$ mutants tested were poor competitors of the $\mathrm{S}$ isolates in the absence of any fungicide selection pressure. The decline of the resistance frequency was sharp even after the first disease cycle, leading to a dominance of the $\mathrm{S}$ isolates. After the end of the fourth disease cycle, the frequency of the H272R/G143A, H272Y/G143A, H272L/G143A, $\mathrm{N} 230 \mathrm{I} / \mathrm{G} 143 \mathrm{~A}$, and P225F/G143A mutants was only 2.4, 1.6, 2.0, 1.8 , and $3.4 \%$, respectively (Table 6).

In the competition experiments conducted using mixed genotype inoculums of S, H272R/G143A, H272Y/G143A, H272L/G143A, N230I/G143A, and P225F/G143A isolates at the initial ratio of $1: 1: 1: 1: 1: 1$, in the absence of any fungicide, selection pressure was found a stepwise increase of the sensitive subpopulation (Fig. 1A). After four disease cycles, the spores of the sensitive isolates were found at a frequency of $64.4 \%$, significantly higher $(P<0.05)$ than the initial frequency of $16.7 \%$ (Fig. 1A). At the same time, fractions of both the $\mathrm{B}^{\mathrm{R}} \mathrm{F}^{\mathrm{S}}$ and $\mathrm{B}^{\mathrm{R}} \mathrm{F}^{\mathrm{R}}$ isolates were reduced at frequencies of 11.6 and $24 \%$, respectively (Fig. 1A). Identification of the $s d h \mathrm{~B}$ mutations in the $\mathrm{B}^{\mathrm{R}} \mathrm{F}^{\mathrm{S}}$ and $\mathrm{B}^{\mathrm{R}} \mathrm{F}^{\mathrm{R}}$ isolates obtained from the diseased fruit after the end of the fourth disease cycle showed that the frequency of all the mutants had been significantly reduced compared with the initial frequency, with values of 12 to $2 \%$ (Fig. 2).

In contrast, when competition was conducted on apple fruit treated with a sublethal dose of boscalid, the frequency of the $S$ isolates declined rapidly, leading to their complete disappearance after the third disease cycle (Fig. 1B). The frequency of the $\mathrm{B}^{\mathrm{R}} \mathrm{F}^{\mathrm{S}}$ phenotype showed a stepwise decrease in the presence of boscalid, with a value of $16.6 \%$ at the end of the fourth disease cycle, whereas the $\mathrm{B}^{\mathrm{R}} \mathrm{F}^{\mathrm{R}}$ phenotype dominated the population, with a frequency of $83.4 \%$ (Fig. 1B). Identification of the $s d h \mathrm{~B}$ mutations in boscalid- or fluopyram-resistant isolates collected after the end of the fourth disease cycle showed that isolates with

TABLE 4. Viability (\%) of sclerotia of Botrytis cinerea isolates possessing $s d h \mathrm{~B}$ or the cytb G143A mutations, stored at three different temperatures for several storage periods

\begin{tabular}{|c|c|c|c|c|c|c|c|c|c|}
\hline \multirow[b]{3}{*}{ Genotype } & \multicolumn{9}{|c|}{ Viability $(\%)$ for each storage temperature and period ${ }^{\mathrm{Z}}$} \\
\hline & \multicolumn{3}{|c|}{$-20^{\circ} \mathrm{C}$} & \multicolumn{3}{|c|}{$20^{\circ} \mathrm{C}$} & \multicolumn{3}{|c|}{$37^{\circ} \mathrm{C}$} \\
\hline & 1 month & 2 months & 4 months & 1 month & 2 months & 4 months & 1 month & 2 months & 4 months \\
\hline Sensitive & 100 & 100 & $86.6 \mathrm{a}$ & 100 & 100 & $92.0 \mathrm{a}$ & 100 & $34.6 \mathrm{a}$ & 0.0 \\
\hline G143A & 100 & 100 & $89.8 \mathrm{a}$ & 100 & 100 & $93.2 \mathrm{a}$ & 100 & $32.8 \mathrm{a}$ & 0.0 \\
\hline H272R/G143A & 100 & 100 & $68.3 \mathrm{~b}$ & 100 & 100 & $80.0 \mathrm{~b}$ & 100 & $22.6 \mathrm{~b}$ & 0.0 \\
\hline H272Y/G143A & 100 & 100 & $67.2 \mathrm{~b}$ & 100 & 100 & $85.0 \mathrm{ab}$ & 100 & $20.6 \mathrm{~b}$ & 0.0 \\
\hline H272L/G143A & 100 & 100 & $43.3 \mathrm{c}$ & 100 & 100 & $68.3 \mathrm{c}$ & 100 & $0.0 \mathrm{~d}$ & 0.0 \\
\hline N230I/G143A & 100 & 100 & $64.0 \mathrm{~b}$ & 100 & 100 & $90.0 \mathrm{ab}$ & 100 & $16.6 \mathrm{bc}$ & 0.0 \\
\hline P225F/G143A & 100 & 100 & $28.7 \mathrm{~d}$ & 100 & 100 & $63.6 \mathrm{c}$ & 100 & $9.1 \mathrm{c}$ & 0.0 \\
\hline
\end{tabular}

${ }^{\mathrm{z}}$ Mean values of groups followed by the same letter are not significantly different according to Fisher's protected least significant difference test at $P=0.05$. Percentage values were arcsine transformed before the statistical analysis.

TABLE 5. Effect of diquat on the mycelial growth and spore germination of Botrytis cinerea isolates with resistance to quinone outside inhibitors or succinate dehydrogenase inhibitors associated with the cytb G143A and several sdhB mutations

\begin{tabular}{|c|c|c|c|c|c|c|c|c|}
\hline \multirow[b]{3}{*}{ Genotype } & \multicolumn{8}{|c|}{ Diquat concentration $(\%)^{\mathrm{z}}$} \\
\hline & \multicolumn{2}{|c|}{$1 \mu \mathrm{g} \mathrm{ml}^{-1}$} & \multicolumn{2}{|c|}{$10 \mu \mathrm{g} \mathrm{ml}^{-1}$} & \multicolumn{2}{|c|}{$100 \mu \mathrm{g} \mathrm{ml}^{-1}$} & \multicolumn{2}{|c|}{$1,000 \mu \mathrm{g} \mathrm{ml}^{-1}$} \\
\hline & RIMG & RISG & RIMG & RISG & RIMG & RISG & RIMG & RISG \\
\hline G143A & $1.5 \mathrm{~b}$ & 0.0 & $7.9 \mathrm{c}$ & 0.0 & $23.4 \mathrm{~d}$ & $0.0 \mathrm{~d}$ & $52.8 \mathrm{~d}$ & 100 \\
\hline H272R/G143A & $8.6 \mathrm{a}$ & 0.0 & $22.7 \mathrm{a}$ & 0.0 & $49.4 \mathrm{~b}$ & $36.2 \mathrm{c}$ & $96.4 \mathrm{ab}$ & 100 \\
\hline H272Y/G143A & $11.0 \mathrm{a}$ & 0.0 & $15.7 \mathrm{~b}$ & 0.0 & $21.3 \mathrm{~d}$ & $51.2 \mathrm{~b}$ & $54.9 \mathrm{~d}$ & 100 \\
\hline H272L/G143A & $1.6 \mathrm{~b}$ & 0.0 & $5.0 \mathrm{~cd}$ & 0.0 & $38.1 \mathrm{c}$ & $63.7 \mathrm{a}$ & $100.0 \mathrm{a}$ & 100 \\
\hline
\end{tabular}

${ }^{\mathrm{z}} \mathrm{RIMG}=$ relative inhibition of mycelial growth and RISG $=$ relative inhibition of spore germination. Mean relative inhibition values of groups followed by the same letter are not significantly different according to Fisher's protected least significant difference test at $P=0.05$. Values were arcsine transformed before statistical analysis.

TABLE 6. Competition in pairs of sensitive (S) and succinate dehydrogenase inhibitor- or quinone outside inhibitor-resistant isolates of Botrytis cinerea possessing the cytb G143A and different $s d h$ B mutations, co-inoculated on apple fruit, with an initial ratio of conidial mixture of 1:1

\begin{tabular}{|c|c|c|c|c|c|}
\hline \multirow[b]{2}{*}{ Genotype mixture } & \multicolumn{5}{|c|}{ Resistance frequency ${ }^{z}$} \\
\hline & Initial & First disease cycle & Second disease cycle & Third disease cycle & Fourth disease cycle \\
\hline H272R/G143A:S & 50 & $16.4 *(4.8)$ & $12.8 *(6.1)$ & $5.0 *(5.2)$ & $2.4 *(2.3)$ \\
\hline H272Y/G143A:S & 50 & $21.0 *(7.6)$ & $16.2 *(9.1)$ & $8.8 *(9.6)$ & $1.6^{*}(2.5)$ \\
\hline H272L/G143A:S & 50 & $26.4 *(8.1)$ & $12.6 *(9.3)$ & $2.6 *(2.9)$ & $2.0 *(2.3)$ \\
\hline N230I/G143A:S & 50 & $24.4 *(8.0)$ & $13.6 *(5.5)$ & $6.0 *(11.6)$ & $1.8 *(2.0)$ \\
\hline P225F/G143A:S & 50 & $28.2 *(14.5)$ & $13.4 *(9.2)$ & $8.4 *(7.4)$ & $3.4 *(2.5)$ \\
\hline
\end{tabular}

${ }^{\mathrm{z}}$ Resistance frequency was determined by testing the germination of conidia on YBA agar medium amended with boscalid at $1 \mu \mathrm{g} \mathrm{ml}{ }^{-1}$. Numbers in parentheses are standard deviation values; $*$ indicates that the observed resistance frequency was significantly different from the initial according to a $\chi^{2}$ test at $P=0.05$. 
single resistance to boscalid were only of the H272R genotype at a frequency of $16.8 \%$, while the fluopyram-resistant isolates were either H272L or P225F genotype at frequencies of 50 and $34 \%$, respectively (Fig. 2).

When the same competition experiment was conducted on apple fruit treated with fluopyram, a rapid disappearance of both $\mathrm{S}$ and $\mathrm{B}^{\mathrm{R}} \mathrm{F}^{\mathrm{S}}$ isolates from the first disease cycle was observed while, at the same time, $\mathrm{B}^{\mathrm{R}} \mathrm{F}^{\mathrm{R}}$ isolates dominated the population, with a frequency of $100 \%$ (Fig. 1C). Identification of the $s d h \mathrm{~B}$ mutants associated with the $\mathrm{B}^{\mathrm{R}} \mathrm{F}^{\mathrm{R}}$ phenotype showed that the same genotypes $\mathrm{H} 272 \mathrm{~L}$ and $\mathrm{P} 225 \mathrm{~F}$ were present in the population at frequencies of 36 and $64 \%$, respectively, while the third $\mathrm{B}^{\mathrm{R}} \mathrm{F}^{\mathrm{R}}$ phenotype, N230I, had also disappeared form the population (Fig. 2).

\section{DISCUSSION}

In the current study, the fitness and the competitive ability of $B$. cinerea with dual resistance to QoIs and SDHIs were investigated. Both fungicide groups inhibit fungal respiration and are of great importance for the successful control of the disease. Although it is

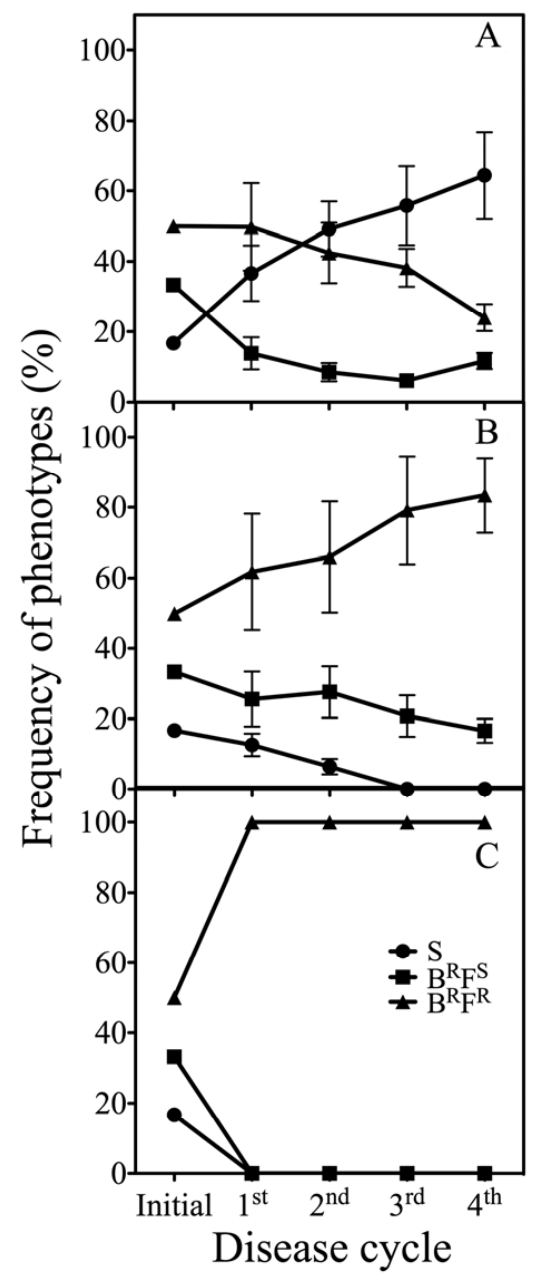

Fig. 1. Competition in vivo between sensitive and succinate dehydrogenase inhibitor- or quinone outside inhibitor-resistant isolates of Botrytis cinerea possessing $\mathrm{H} 272 \mathrm{~L} / \mathrm{R} / \mathrm{Y}, \mathrm{P} 225 \mathrm{~F}$, and N230I $s d h \mathrm{~B}$ and the $c y t \mathrm{~b}$ G143A mutations, co-inoculated on $\mathbf{A}$, fungicide-untreated; $\mathbf{B}$, boscalid-treated; and $\mathbf{C}$, fluopyram-treated apple fruit with an initial ratio of 1:1:1:1:1:1 conidia. Observed phenotypes: $\mathrm{S}=$ conidia of wild-type sensitivity; $\mathrm{B}^{\mathrm{R}} \mathrm{F}^{\mathrm{S}}=$ boscalidresistant and fluopyram-sensitive conidia corresponding to H272R or H272Y mutants; and $\mathrm{B}^{\mathrm{R}} \mathrm{F}^{\mathrm{R}}=$ boscalid- and fluopyram-resistant conidia, corresponding to $\mathrm{P} 225 \mathrm{~F}$ or $\mathrm{N} 230 \mathrm{I}$ or $\mathrm{H} 272 \mathrm{~L}$ mutants. Vertical lines indicate the standard error of the mean well established that resistance to QoIs in field isolates of several plant pathogens, associated with the G143A substitution in cytb, do not entail a fitness cost $(3,9,18)$, there is limited information on the effect of $s d h \mathrm{~B}$ mutations to the fitness of the SDHIresistant fungal plant pathogens $(12,20,21,31)$.

The isolates selected for the study were all field isolates and were divided into groups based on the $s d h \mathrm{~B}$ mutation present in their genome. However, all the SDHI-resistant isolates were also resistant to QoIs and possessed the G143A mutation in cytb. Dual resistance to QoIs and SDHIs due to independent target-site mutations is the most common phenotype in $B$. cinerea isolates not only in Greece $(6,38)$ but also in several other places worldwide $(11,19,24)$. The absence of field isolates with single resistance to SDHIs suggests that resistance to SDHIs emerged after the emergence of QoIs resistance, while the use of pyraclostrobin and boscalid in a prepacked mixture co-selects resistance to both fungicide classes (11).

In this study, measurements of the several fitness components were conducted under both optimal and marginal conditions for the growth, survival, and reproduction of the pathogen. This is of particular importance because the pathogen is exposed to highly variable conditions throughout the year in different habitats (7). The results of the study showed that isolates with single resistance to QoIs did not suffer any fitness cost. This finding is in agreement with previous studies reporting that QoI resistance in field isolates of $B$. cinerea do not affect the fitness of the resistant strains $(4,20)$ and suggests that any fitness cost observed in our study in isolates with dual resistance might be due to the presence of $s d h \mathrm{~B}$ mutations.

In contrast to the group of isolates with single resistance to QoIs, most of the isolate groups with dual resistance to SDHIs and QoIs associated with the different $s d h \mathrm{~B}$ mutations and the G143A mutation were found to suffer significant fitness cost. Isolates possessing the $\mathrm{H} 272 \mathrm{R}$ substitution showed aggressiveness and spore production ability similar to that of the group of sensitive isolates but lower mycelial growth and sclerotia viability. In contrast, the remaining groups of $s d h \mathrm{~B}$-mutated isolates showed significantly lower values compared with the group of sensitive isolates for most, if not all, fitness components tested. Such findings seem to be in contrast to the data presented recently by Kim and Xiao (20), who reported that $B$. cinerea isolates from apple with dual resistance to SDHIs and QoIs showed fitness similar to that of the sensitive isolates. However, in this report, no information is provided related to the $s d h$ mutations associated

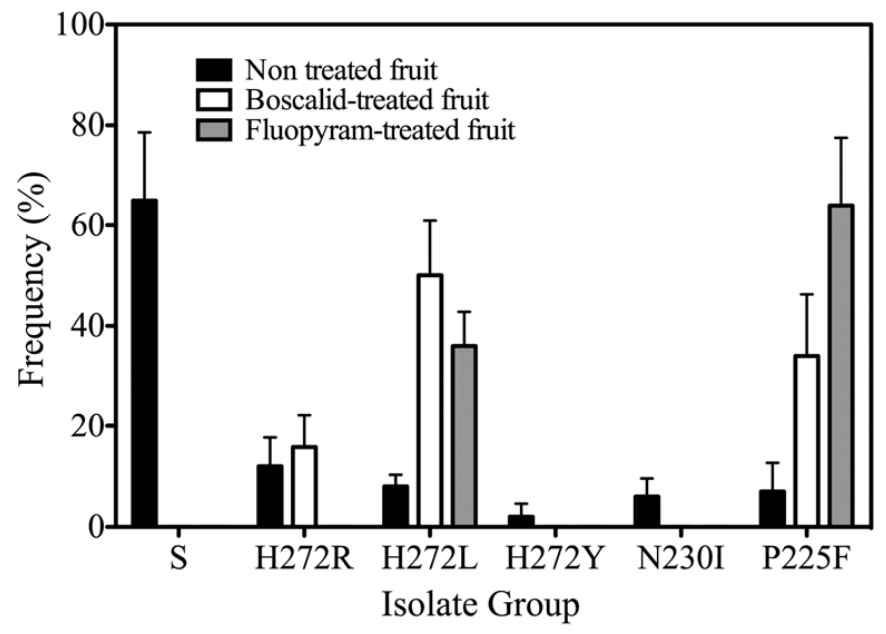

Fig. 2. Observed frequencies of sensitive (S) and $s d h \mathrm{~B}$ mutant isolates of Botrytis cinerea, co-inoculated on fungicide-untreated (solid bar), boscalidtreated (white bar), and fluopyram-treated (shaded bar) apple fruit with an initial ratio of 1:1:1:1:1:1 conidia, after 4 disease cycles. Vertical lines indicate the standard error of the mean. 
with resistance to SDHIs. Although a natural variability is expected when different isolates are used in fitness studies, it might be assumed that, within the isolates used in their study, the majority possessed the H272R mutation, taking into account that, in an earlier report of the same research team, H272R was predominant in the pathogen population that they studied (44). More recently, Laleve et al. (21) reported that isogenic strains of $B$. cinerea possessing several $s d h \mathrm{~B}$ mutations showed a high fitness cost compared with the wild-type strain. In that study, the H272R and P225L mutants showed the strongest fitness modifications. Information on the effect of $s d h \mathrm{~B}$ mutations in other pathosystems is rather limited, with contradictory results. In a recent report, Fraaje et al. (12) provided some evidence for lower fitness in H267L (the homolog of H272L in B. cinerea) mutants of Mycosphaerella graminicola whereas, in other mutants, variable results were obtained. For the same pathogen, another group reported that several recombinant strains possessing different $s d h$ mutations did not suffer fitness penalties, although there was a biological impact in planta (31).

The increased fitness of isolates possessing the H272R substitution compared with that of the remaining $s d h \mathrm{~B}$ mutants can explain the predominance or the high frequency of this genotype within SDHI-resistant subpopulations of $B$. cinerea, wherever resistance to this fungicide group has been emerged $(11,19,38)$. In contrast, isolates with other mutations such as the $\mathrm{P} 225 \mathrm{~F}$ or the H272L have been detected in the field only rarely and in very low frequencies. This is rather unexpected, taking into account that both P225F and H272L confer very high levels of resistance to boscalid $(24,39)$. Furthermore, recent experimental data showed that boscalid treatments provided moderate or low control efficacy against H272R and H272Y mutants while totally failing to control P225F or H272L mutants (39).

Sclerotia are considered to be the most important mycelial structures involved in the survival of B. cinerea in the field under adverse environmental conditions (16). Thus, the number of sclerotia produced by a pathogen strain along with their survival ability under various environmental conditions can affect overseasoning of the fungus during winter or summer periods, when the pathogen is inactive. The results of our study showed that, at $20^{\circ} \mathrm{C}$, isolates possessing the $\mathrm{H} 272 \mathrm{R}$ or $\mathrm{H} 272 \mathrm{~L}$ mutations produced significantly higher numbers of sclerotia compared with the remaining groups of isolates while, at the marginal for growth temperature of $7^{\circ} \mathrm{C}$, all the $s d h \mathrm{~B}$-mutated isolates, with the exception of $\mathrm{H} 272 \mathrm{Y}$ isolates, also produced significantly more sclerotia. However, despite the higher sclerotia production by most of $s d h \mathrm{~B}$ mutants, they showed significantly lower viability compared with wild-type isolates and isolates with single resistance to QoIs. The observed reduction in viability of sclerotia in $s d h \mathrm{~B}$ mutants is possibly correlated with the reduced size of these sclerotia. Such a finding may have important implications for the dynamics of $s d h \mathrm{~B}$ mutation frequency in the fields. Based on these laboratory observations, it is hypothesized that, after the hot summer period or the cold winter period, a reduction in the frequency of $\mathrm{H} 272 \mathrm{~L}$ or $\mathrm{P} 225 \mathrm{~F}$ mutants will be observed due to the lower viability of the sclerotia of these strains. Continuous monitoring during the entire vegetative period and not only during the fungicide spray application period is required to confirm this hypothesis.

The increased number of sclerotia produced by the $s d h \mathrm{~B} \mathrm{mu}-$ tants might be related to higher reactive oxygen species (ROS) production in these isolates. The mitochondrial respiratory chain and, in particular, complexes I, II, and III are considered to be primary sources of $\operatorname{ROS}(8,43)$. Mutations in $s d h$ of several organisms associated with impaired enzyme activity have been found to contribute in increased levels of ROS with several biological influences $(31,34,41)$ In $B$. cinerea, ROS regulatory systems are known to control cellular differentiation, including sclerotia production and pathogenicity (35).
The results of this study showed that the isolates possessing the $s d h \mathrm{~B}$ mutations were more sensitive to oxidation stress imposed by diquat amendment in the growth medium compared with sensitive isolates or the isolates with single resistance to QoIs. A similar sensitivity to the oxidative stress has been observed in H277R/Y (homolog replacements of H272R/Y) mutants of Alternaria alternata (2). Similarly, $s d h \mathrm{~B}, s d h \mathrm{C}$, and $s d h \mathrm{D}$ mutations have been found to confer increased ROS production and hypersensitivity to oxidative stress in other microorganisms such as Escherichia coli and Saccharomyces cerevisiae $(15,34)$ but not in the hemibiotrophic fungus $M$. gramminicola (31). In the current study, the observed sensitivity of $s d h \mathrm{~B}$ mutants to oxidation stress may explain the lower mycelial growth and the lower pathogenicity reported in individual fitness component measurements. B. cinerea, as a necrotrophic pathogen, benefits from hostinduced elevated ROS production that enhances mycelial growth and pathogenicity $(14,35)$. However, because the fungus itself is sensitive to ROS, it possesses a ROS-regulatory system enabling detoxification of ROS within fungal cells by catalases and peroxidases $(35,36)$. Further research is required to clarify the precise mechanism of the observed sensitivity to oxidative stress in the pathogen isolates with $s d h \mathrm{~B}$ mutations.

In this study, fitness was evaluated not only in terms of "predicted fitness" (measurement of several components in individual isolates) but also in terms of "realized fitness" (competition between sensitive and resistant isolates in vivo leading to genotype frequency changes). Although the isolates used in the study had been collected from strawberry, the competition experiments were conducted on apple fruit, following a procedure described previously, with slight modifications (20). Intensive spoilage of strawberry fruit after inoculation with $B$. cinerea, due to the growth of secondary bacterial and fungal saprophytes, does not allow the manipulation of the fruit for the preparation of inoculum for subsequent inoculation cycles. The results of the study showed that, when competition experiments were conducted using separate pairs of each mutated genotype with the isolates of wild-type sensitivity at an initial ratio of $1: 1$, the sensitive isolates dominated in all the tested pairs. The dominance of the sensitive isolates over the mutated isolates was in agreement with the results obtained from the individual fitness components measurements, suggesting a lower fitness for the mutated strains. A similar predominance of sensitive isolates was observed in competition experiments conducted by Kim and Xiao (20) on apple fruit.

Competition experiments conducted using mixed-genotype inocula at a ratio of $1: 1: 1: 1: 1: 1$ in the absence of fungicide selection pressure and in the presence of either boscalid or fluopyram selection pressure showed that sensitive isolates dominated in the population when they were competing with the mutated isolates in the absence of selection pressure. Such results suggest that the discontinued use of SDHIs in the field may contribute to a decrease of frequency of SDHI-resistant genotypes. Evidence of this was recently obtained from monitoring data of sensitivity to SDHIs obtained from kiwifruit orchards in Greece (G. S. Karaoglanidis, unpublished data). Fungicide sensitivity measurements in $B$. cinerea isolates collected from kiwifruit obtained from these orchards in 2010 had shown high frequencies of resistance to SDHIs and QoIs (6). After that, the use of SDHIs and QoIs was discontinued in these orchards and a monitoring conducted during 2013 showed that, within these orchards, the strains with resistance to SDHIs and QoIs had disappeared (G. S. Karaoglanidis, unpublished data). In contrast, when the competition experiment was conducted in the presence of boscalid, a rapid or slow decrease of wild-type and $\mathrm{B}^{\mathrm{R}} \mathrm{F}^{\mathrm{S}}$ strains, respectively, was observed, while $\mathrm{B}^{\mathrm{R}} \mathrm{F}^{\mathrm{R}}$ strains rapidly increased. Identification of the $s d h \mathrm{~B}$ mutations in the selected isolates showed that $\mathrm{H} 272 \mathrm{~L}$ and $\mathrm{P} 225 \mathrm{~F}$ mutants were dominant in the population. Such a result may seem unexpected, taking into account that $\mathrm{H} 272 \mathrm{~L}$ and 
$\mathrm{P} 225 \mathrm{~F}$ are rare mutations in the fields. However, in our experimental conditions, the fungal strains were under constant selection pressure imposed by the boscalid treatments whereas, in the field, there are long periods of time without fungicide selection pressure. Furthermore, the high levels of resistance to boscalid conferred by the H272L and P225F mutations compared with the moderate levels of resistance conferred by H272R, H272Y, and N230I mutations $(24,39)$ can explain the observed predominance of $\mathrm{H} 272 \mathrm{~L}$ and $\mathrm{P} 225 \mathrm{~F}$ mutants in the competition experiment conducted under constant boscalid selection pressure. A similar rapid selection of $\mathrm{H} 272 \mathrm{~L}$ and $\mathrm{P} 225 \mathrm{~F}$ was also observed when the competition experiment was conducted in the presence of fluopyram. Obviously, fluopyram treatments eliminated the sensitive and $\mathrm{H} 272 \mathrm{R} / \mathrm{Y}$ isolates that are fluopyram sensitive and retarded the growth of N230I isolates that are only moderately resistant to fluopyram (39). Such results suggest that introduction into the spray programs of newer SDHI fungicides such as fluopyram may lead to changes in the type of mutations associated with resistance to SDHIs dominating in the fungal population.

The observed fitness penalty in isolates of $B$. cinerea with dual resistance to SDHIs and QoIs associated with different mutations in $s d h \mathrm{~B}$ and the cytb G143A, reported in the current study, may have important implications for disease management. Antiresistance strategies aim to slow down resistance frequencies by decreasing the rate of the resistance alleles using fungicides that belong to different chemical classes. Applications of these fungicides in alternation schemes with SDHIs could contribute to a decrease in the SDHI or QoI resistance frequency. Newer SDHI molecules such as fluopyram should decrease the frequency of non-cross-resistant $s d h \mathrm{~B}$ mutants such as $\mathrm{H} 272 \mathrm{R} / \mathrm{Y}$ but likely select for the other, rarer preexisting or newer genotypes. The alternation of different SDHIs within the same season may increase the frequency of cross-resistant genotypes at the end of the season, emphasizing the importance of properly defined spray programs and the use of an appropriate mixture partner.

\section{ACKNOWLEDGMENTS}

This research has been co-financed by the European Union (European Social Fund [ESF]) and Greek national funds through the Operational Program "Education and Lifelong Learning" of the National Strategic Reference Framework-Research Funding Program THALES, project M15380264, entitled "Development of IT and molecular diagnostics tools for improving the sustainabiliy of pesticide based approaches to control agricultural pests of major economic importance in Greece." We thank BASF Hellas S.A. and Bayer CropScience Hellas A.G. for providing pure technical grades of boscalid and fluopyram. The article is dedicated to the unforgettable memory of our colleague Anastasios N. Markoglou, who passed away suddenly in August 2012.

\section{LITERATURE CITED}

1. Amiri, A., Heath, S. M., and Peres, N. N. 2012. New insights into mechanisms of resistance to respiration inhibitor fungicides in Botrytis cinerea. (Abstr.) Phytopathology 102:S4.4.

2. Avenot, H. F., Sellam, A., and, Michailides, T. J. 2009. Characterization of mutations in the membrane-anchored subunits AaSDHC and AaSDHD of succinate dehydrogenase from Alternaria alternata isolates conferring field resistance to the fungicide boscalid. Plant Pathol. 58:1134-1143.

3. Avila-Adame, C., and Köller, W. 2003. Characterization of spontaneous mutants of Magnaporthe grisea expressing stable resistance to the QoI inhibiting fungicide azoxystrobin. Curr. Genet. 42:332-338.

4. Banno, S., Yamashita, K., Fukumori, F., Okada, K., Uekusa, H., Takagaki, M., Kimura, M., and Fujimura M, 2009. Characterization of QoI resistance in Botrytis cinerea and identification of two types of mitochondrial cytochrome $b$ gene. Plant Pathol. 58:120-129.

5. Bartlett, D. W., Clough, J. M., Godwin, J. R., Hall, A. A., Hamer, M., and Parr-Dobrzanski, B. 2002. The strobilurin fungicides. Pest Manage. Sci. 58:649-662.

6. Bardas, G. A., Veloukas, T., Koutita, O., and Karaoglanidis, G. S. 2010. Multiple resistance of Botrytis cinerea from kiwifruit to SDHIs, QoIs and fungicides of other chemical groups. Pest Manage. Sci. 66:967-973.
7. Billard, A., Fillinger, S., Leroux P., Lachaise H., Beffa, R., and Debieu, D. 2012. Strong resistance to the fungicide fenhexamid entails a fitness cost in Botrytis cinerea, as shown by comparisons of isogenic strains. Pest Manage. Sci. 68:684-691.

8. Cecchini, G. 2003. Function and structure of complex II of the respiratory chain. Annu. Rev. Biochem. 72:77-109.

9. Chin, K. M., Chavaillaz, D., Kaesbohrer, M., Staub, T., and Felsenstein, F. G. 2001. Characterizing resistance risk of Erysiphe graminis f. sp. tritici to strobilurins. Crop Prot. 20:87-96.

10. Elad, Y., Williamson, B., Tudzynski, P., and Delen, N. 2004. Botrytis spp. and diseases they cause in agricultural systems - an introduction. Pages 18 in: Botrytis: Biology, Pathology and Control. Y. Elad, B. Williamson, P. Tudzynski, and N. Delen, eds. Springer, Dordrecht, The Netherlands.

11. Fernandez-Ortuno, D., Chen, F., and Schnabel, G. 2012. Resistance to pyraclostrobin and boscalid in Botrytis cinerea isolates from strawberry in the Carolinas. Plant Dis. 96:1198-1203.

12. Fraaje, B. A., Bayon, C., Atkins, S., Cools, H. J., Lucas, J. A., and Fraaje, M. W. 2012. Risk assessment studies on succinate dehydrogenase inhibitors, the new weapons in the battle to control Septoria leaf blotch in wheat. Mol. Plant Pathol. 13:263-275.

13. Fournier, E., Levis, C., Fortini, D., Leroux, P., Giraud, T., and Brygoo, Y. 2003. Characterization of Bc-hch, the Botrytis cinerea homolog of the Neurospora crassa het-c vegetative incompatibility locus, and its use as a population marker. Mycologia 95:251-261.

14. Govrin, E. M., and Levine, A. 2000. The hypersensitive response facilitates plant infection by the necrotrophic pathogen Botrytis cinerea. Curr. Biol. 10:751-757.

15. Guo, J., and Lemire, B. D. 2003. The ubiquinone-binding site of the Saccharomyces cerevisiae succinate-ubiquinone oxidoreductase is a source of superoxide. J. Biol. Chem. 278:47629-47635.

16. Holz, G., Coertze, S., and Williamson, B. 2004. The ecology of Botrytis on plant surfaces. Pages 9-27 in: Botrytis: Biology, Pathology and Control. Y. Elad, B. Williamson, P. Tudzynski, and N. Delen, eds. Springer, Dordrecht, The Netherlands.

17. Jeger, M. J., Wijngaarden, P. J., and Hoekstra, R. F. 2008. Adaptation to the cost of resistance in a haploid clonally reproducing organism: the role of mutation, migration and selection. J. Theor. Biol. 252:621-632.

18. Karaoglanidis, G. S., Luo, Y., and Michailides, T. J. 2011. Competitive ability and fitness of Alternaria alternata isolates resistant to QoI fungicides. Plant Dis. 95:178-182.

19. Kim, Y. K., and Xiao, C. L. 2010. Resistance to pyraclostrobin and boscalid in populations of Botrytis cinerea from stored apples in Washington State. Plant Dis. 94:604-612.

20. Kim, Y. K., and Xiao, C. L. 2011. Stability and fitness of pyraclostrobinand boscalid-resistant phenotypes in field isolates of Botrytis cinerea from apple. Phytopathology 101:1385-1391.

21. Laleve, A., Walker, A.-S., Gamer, S., Toquin, V., Debieu, D., and Fillinger, S. 2013. From enzyme to fungal development or how $S d h \mathrm{~B}$ mutations impact respiration, fungicide resistance and fitness in the grey mold agent Botrytis cinerea. Page 80 in: (Abstr.) Modern Fungicides and Antifungal Compounds-17th Int. Reinhardsbrunn Symp. Friedricroda, Germany.

22. Leroch, M., Kretchmer, M., and Hahn, M. 2011. Fungicide resistance phenotypes of Botrytis cinerea isolates from commercial vineyards in South West Germany. J. Phytopathol. 159:63-65.

23. Leroux, P., Fritz, R., Debieu, D., Albertini, C., Lanen, C., Bach, J., Gredt, M., and Chapeland, F. 2002. Mechanisms of resistance to fungicides in field strains of Botrytis cinerea. Pest Manage. Sci. 58:876-888.

24. Leroux, P., Gredt, M., Leroch, M., and Walker, A.-S. 2010. Exploring mechanisms of resistance to respiratory inhibitors in field strains of Botrytis cinerea, the causal agent of gray mold. Appl. Environ. Microbiol. 76:6615-6630

25. Matsson, M., and Hederstedt, L. 2001. The carboxin-binding site on Paracoccus denitrificans succinate:quinone reductase identified by mutations. J. Bioenerg. Biomembr. 33:99-105.

26. Mosbach, A., Leroch, M., Mendgen, K. W., and Hahn, M. 2011. Lack of evidence for a role of hydrophobins in conferring surface hydrophobicity to conidia and hyphae of Botrytis cinerea. BMC Microbiol. 11:10.

27. Myresiotis, C. K., Karaoglanidis, G. S., and Tzavella-Klonari, K. 2007. Monitoring for resistance of Botrytis cinerea isolates from vegetable crops to anilinopyrimidine, phenylpyrrole, hydroxyanilide, benzimidazole and dicarboximide fungicides. Plant Dis. 91:407-413.

28. Parnell, S., Gilligan, C. A., and Van den Bosch, F. 2005. Small-scale fungicide spray heterogeneity and the coexistence of resistant and sensitive pathogen strains. Phytopathology 95:632-639.

29. Pringle, A., and Taylor, J. W. 2002. The fitness of filamentous fungi. Trends Microbiol. 10:474-481.

30. Samuel, S., Papayiannis, L. C., Leroch, M., Veloukas, T., Hahn, M., and Karaoglanidis, G. S. 2011. Evaluation of the incidence of the G143A mutation and $c y t b$ intron presence in the cytochrome $b c l$ gene conferring 
QoI resistance in Botrytis cinerea populations from several hosts. Pest Manage. Sci. 67:1029-1036.

31. Scalliet, G., Bowler, J., Luksch, T., Kirchhofer-Allan, L., Steinhauer, D., Ward, K., Niklaus, M., Verras, A., Csukai, M., Daiana, A., and FonnePfister, R. 2012. Mutagenesis and functional studies with succinate dehydrogenase inhibitors in the wheat pathogen Mycosphaerella graminicola. PLoS One 7:e35429.

32. Sierotzki, H., and Scalliet, G. 2013. A review of current knowledge of resistance aspects for the next generation succinate dehydrogenase inhibitor fungicides. Phytopathology 103:880-887.

33. Stammler, G., Brix, H. D., Nave, B., Gold, R., and Schoefl, U. 2008. Studies on the biological performance of boscalid and its mode of action. Pages 45-51 in: Modern Fungicides and Antifungal Compounds. V. H. W. Dehne, H. B. Deising, U. Gisi, P. E. Russell, and H. Lyr, eds. Deutsche Phytomedizinische Gesellschaft, Braunschweig, Germany.

34. Szeto, S. S., Reinke, S. N., Sykes, B. D., and Lemire, B. D. 2007. Ubiquinone-binding site mutations in the Saccharomyces cerevisiae succinate dehydrogenase generate superoxide and lead to the accumulation of succinate. J. Biol. Chem. 282:27518-27526.

35. Temme, N., and Tudzynski, P. 2009. Does Botrytis cinerea ignore $\mathrm{H}_{2} \mathrm{O}_{2}$ induced oxidative stress during infection? Characterization of Botrytis activator protein1. Mol. Plant-Microbe Interact. 22:987-998.

36. Tudzynski, P., and Kokkelink, L. 2008. Botrytis cinerea: Molecular aspects of a necrotrophic life-style. Pages 29-50 in: The Mycota, Vol. V. Plant Relationships. H. Deising, ed. Springer, Heidelberg, Germany.

37. Veloukas, T., and Karaoglanidis, G. S. 2012. Biological activity of the succinate dehydrogenase inhibitor fluopyram against Botrytis cinerea and fungal baseline sensitivity. Pest Manage. Sci. 68:858-864.

38. Veloukas, T., Leroch, M., Hahn, M., and Karaoglanidis, G. S. 2011 Detection and molecular characterization of boscalid-resistant Botrytis cinerea isolates from strawberry. Plant Dis. 95:1302-1307.

39. Veloukas, T., Markoglou, A. N., and Karaoglanidis, G. S. 2013. Differential effect of $S d h B$ gene mutations on the sensitivity to SDHI fungicides in Botrytis cinerea. Plant Dis. 97:118-122.

40. Walker, A.-S., Micoud, A., Remuson, F., Grosman, J., Gredt, M., and Leroux, P. 2013. French vineyards provide information that opens ways for effective resistance management of Botrytis cinerea (grey mould). Pest Manage. Sci. 69:667-678.

41. Walker, D. W., Hajek, P., Muffat, J., Knoepfle D., Cornelison, S., Attardi, G., and Benzer, S. 2006. Hypersensitivity to oxygen and shortened lifespan in a Drosophila mitochondrial complex II mutant. Proc. Natl. Acad. Sci. USA 103:16382-16387.

42. Weber, R. W. S. 2011. Resistance of Botrytis cinerea to multiple fungicides in Northern German small-fruit production. Plant Dis. 95:12631269.

43. Yankovskaya, V., Horsefield, R., Tornroth, S., Luna-Chavez, C., Miyoshi, H., Leger, C., Byrne, B., Cecchini, G., and Iwata, S. 2003. Architecture of succinate dehydrogenase and reactive oxygen species generation. Science 299:700-704.

44. Yin, Y. N., Kim, Y. K., and Xiao, C. L. 2011. Molecular characterization of boscalid resistance in field isolates of Botrytis cinerea from apple. Phytopathology 101:986-995. 